\title{
AS FACES DE BAKHTIN: UMA ANÁLISE DISCURSIVA DE CAPAS DE LIVROS
}

\author{
Marcos Lúcio de Sousa Góis* \\ Universidade Federal da Grande Dourados \\ Faculdade de Comunicação, Artes e Letras \\ Dourados, MS, Brasil
}

\begin{abstract}
Resumo: Este ensaio apresenta uma análise discursiva das capas suiça, brasileira e espanhola do livro de Jean-Paul Bronckart e Cristian Bota, intitulado em português Bakhtin desmascarado: história de um mentiroso, de uma fraude, de um delirio coletivo. Fundamentando-se na perspectiva dialógica de discurso e dialogando com a psicanálise e a semiótica, objetiva compreender os efeitos de sentidos produzidos por esses enunciados. São dois os motivos para tal proposta: primeiro, o livro de Bronckart e Bota provocou certo desconforto acadêmico; segundo, este desconforto gerou inúmeros debates a respeito da natureza da obra em foco. Embora as capas tratem aparentemente do mesmo objeto, ambas oferecem ao leitor elementos diferentes para travarem um primeiro contato com essa história. Espera-se com esta análise, além de alimentar o diálogo a respeito da controvérsia na qual se viram envolvidos Bronckart e Bota e seus críticos, reforçar a tese de que o autor-criador Bakhtin transcende o indivíduo Bakhtin.
\end{abstract}

Palavras-chave: Análise Dialógica do Discurso. Enunciados. Sentidos. Capas.

“- Escribir carece de significado - acotó Virgilio -. Es la solapa lo que le otorga un sentido u otro. ¡La solapa es MÁS, MUCHÍSIMO MÁS importante que el libro!”.

(SAMOZA, 2000, p. 46).

1 INTRODUÇÃO

Neste trabalho, apresentamos uma análise discursiva da capa do livro Bakhtin desmascarado: história de um mentiroso, de uma fraude, de um delírio coletivo ${ }^{1}$, de Jean-Paul Bronckart e Cristian Bota ${ }^{2}$, em suas edições suíça, brasileira e espanhola. Não desejamos entrar propriamente no mérito da obra de Bronckart e Bota ${ }^{3}$. Gostaríamos tão

\footnotetext{
* Professor Adjunto IV da FACALE-UFGD. Membro dos grupos de pesquisa GETFOR/UFGD e LAEL/PUC-SP. E-mail: mlsgois2008@uol.com.br.

${ }^{1}$ Em francês: Bakhtine démasqué: Histoire d'un menteur, d'une escroquerie et d'un délire collectif; em espanhol: Bajtín desenmascarado: historia de un mentiroso, una estafa y un delirio colectivo.

${ }^{2}$ A obra foi publicada primeiramente na Suíça (Genebra) em 2011, pela editora DROZ; no ano seguinte, no Brasil (São Paulo), com tradução de Marcos Marcionilo pela editora Parábola. Em 2013 saiu, em Madrid, Espanha, pela Antônio Machado Libros.

${ }^{3}$ Sobre a envergadura acadêmica e científica da obra, há textos críticos que podem ser consultados, dos quais destacamos o conjunto de artigos organizados por Beth Brait (2009a, 2009b), em que se apresentam (reforçam) discussões sobre a questão da "autoria" em textos do filósofo russo e do que se convencionou
} 
somente de mostrar uma perspectiva de análise discursiva das capas (tratadas como enunciados), objetivando compreender seus sentidos e de que modo esses sentidos nos ajudam a entender como "Bakhtin" e "desmascarado" são apreendidos. Para tanto, mobilizamos a Análise Dialógica do Discurso (BRAIT, 2006a, 2006b, 2013), bem como alguns aspectos de Psicanálise (JUNG, 2000, 2008) e de Semiótica da Cultura (GUIMARÃES, 2000). São fundamentais também à argumentação os textos de Bakhtin (1981, 2003, 2010) e Bakhtin/Volochinov (2002).

São dois os motivos para tal trabalho: primeiro, o livro de Bronckart e Bota provocou certo desconforto acadêmico. Segundo, este desconforto levou à reação de inúmeros pesquisadores, como se pode observar, por exemplo, no texto de Zekine, bem como a contrarreação de Bronckart e Bota. Consoante os críticos do texto de Bronckart e Bota, questiona-se o que há (ou haveria) de novo no que escreveram; afinal, há tempos se sabe que Mikhail Bakhtin não é único autor de seus textos. O novo, para nós, não estaria, n'o que foi dito, mas no como. E é justamente nesse ponto que este texto se torna importante. Ao defender a capa enquanto um enunciado verbo-visual que contribui significativamente para o modo como a obra é recebida, também reforça a tese de que o autor-criador Bakhtin transcende o indivíduo Bakhtin.

A princípio, é importante reforçar dois pontos: o primeiro diz respeito à própria questão da autoria. A respeito de quem são as palavras quando se trata de Bakhtin, Volochinov e Medviédev ${ }^{4}$ - sobretudo estes por estarem no centro dos textos disputados - eis uma resposta, nas palavras de Beth Brait:

[...] o pensamento bakhtiniano [é] constituído não somente pelos escritos de Mikhail Mikhalovich Bakhtin (1895-1975), mas também pela produção de intelectuais de diferentes áreas que com ele participaram, nas Rússias compreendidas entre os anos 1920-1970, de vários e produtivos Círculos de discussão e construção de uma postura singular em relação à linguagem e seus estudos (BRAIT, 2009b, p. 9, grifos da autora).

O segundo relaciona-se ao fato de Mikhail Bakhtin ser nome icônico de um conjunto teórico em filosofia da linguagem, em estudos culturais, em estudos literários, etc., fazendo dele não um escritor somente, mas um fundador de discursividade ${ }^{5}$. $\mathrm{Na}$

chamar de Círculo de Bakhtin. Há, ainda, o artigo de Pampa Arán (2014) e as recentes resenhas de Sandra Nossik (2014) e Serge Zenkine (2014), publicados em edição especial da revista Bakhtiniana (jan./jul., 2014). Nessa mesma edição, são importantes os textos de Iúri Pavlovitch Medviédev e Dária Aleksándrovna Medviédeva (2014), respectivamente filho e nora de Medviédev, e o de Frédéric François (2014). Pode-se ler também uma resposta de Bronckart e Bota (Bakhtin desmascarado - Reação às críticas à obra, de 2014), traduzido para o português por Marcos Bagno. Nesse artigo, os autores citam outras resenhas críticas ao próprio livro e buscam dialogar com algumas delas. Não há, todavia, nenhuma observação por parte de Bronckart e Bota em relação aos textos publicados nessa edição especial da Bakhtiniana.

${ }^{4}$ Ocorre-nos a pergunta de Michel Foucault (2001): “Que importa quem fala?", emprestada de Beckett. Importa, no fundo, saber se determinado conjunto de textos forma certo número de conceitos ou de contextos teóricos, que nos parece ser o caso dos textos bakhtinianos.

${ }^{5}$ Bakhtin é um fundador de discursividade (FOUCAULT, 2001, p. 283) não por ser o autor de suas obras, de seus livros, e sim por produzir "alguma coisa a mais: a possibilidade e a regra de formação de outros textos"; estabelecer "a possibilidade infinita de discursos”. Em síntese, tal qual Marx, Freud, Saussure, dentre outros, Bakhtin tornou possível certo número de diferenças em relação a seus textos, a seus conceitos, a suas hipóteses no interior próprio da filosofia da linguagem, dos estudos culturais, etc.. 
prática, Bakhtin deveria importar menos por sua história pessoal (de interesse de um biógrafo, por exemplo, ou, em sua época, de um agente do governo stalinista), e mais por seu trabalho transcender à simples individualidade. Ou, em outros termos, "Bakhtin" é uma transnominação.

Feitas essas considerações iniciais, o texto está deste modo organizado: inicialmente, falamos do objeto capa, apresentando algumas considerações históricas, destacando certo apelo comercial da obra de Bronckart e Bota, ao mesmo tempo em que discorremos a respeito do conjunto teórico desta investigação. Em seguida, trazemos a descrição e a análise das capas do livro de Bronckart e Bota, em suas edições suíça, brasileira e espanhola, publicadas respectivamente nos anos de 2012, 13 e 14. Para a análise, conforme dito no início desta Introdução, mobilizamos, além da Análise do Discurso, alguns aspectos da Psicanálise e da Semiótica. Por fim, apresentamos algumas considerações finais.

\section{CAPAS ENQUANTO ENUNCIADOS: O VERBO-VISUAL}

Toda "capa" é o resultado de um processo (do gerenciamento de signos, ideológicos que são), cujas marcas das divergências e convergências de sua produção não podem ser verificadas em sua totalidade. O que encontramos ao ler capas, portanto, são pistas, meras lembranças das batalhas pela significação.

Analisar capas como textos (ou enunciados concretos ${ }^{6}$ ) não é nenhuma novidade, sendo objeto de interesse de áreas como Letras e História ${ }^{7}$. Aliás, a capa há tempos deixou de ser mero invólucro para conteúdo dos livros, passando a peça importante em sua produção, comercialização, recepção e, particularmente, na produção de sentidos. Bruchard (2014) sustenta, por exemplo, que as capas de algumas obras na Idade Média, por conta do valor monetário de sua confecção, muitas vezes feitas de metal e incrustadas de pedras e com o objetivo de "manter o livro em pé", são consideradas obras de arte, sobremaneira os livros religiosos. Segundo Bruchard, é a partir do século XV que tem início a era brilhante da encadernação de livros, deixando aos poucos "mosteiros" e passando aos ateliês especializados, "que trabalham por encomenda de abastados mecenas, bibliófilos e colecionadores". Em outros termos, começa o início do livro como objeto (do/de desejo) comercial.

Por conta, nos dias atuais, da influência do discurso publicitário na vendagem de livros e em nossas vivências cotidianas, a obra de Bronckart e Bota apresenta, desde a leitura da capa, característico apelo comercial, sobretudo na edição brasileira. Como nos

\footnotetext{
${ }^{6}$ Em nossa análise, amparando-nos em Bakhtin (2003), consideraremos que o enunciado, como unidade real de comunicação, pressupõe uma autoria, sendo determinado pelo querer-dizer, pelo tema e pelo gênero para que seja possível a posição responsiva do "outro" (em resposta à posição do locutor), marcando alternância dos sujeitos falantes. Estamos sustentando-nos na premissa de que o sujeitoenunciador do livro não é o mesmo sujeito-enunciador das capas.

${ }^{7}$ Em pesquisa realizada junto ao banco de dados da Biblioteca Digital Brasileira de Teses e Dissertações (BDTD - <http://bdtd.ibict.br/>), ao digitarmos "capas" no campo "títulos", encontramos 29 referências, distribuídas entre teses e dissertações, que analisam capas diversas: de livros (didáticos ou não), revistas, discos, jornais, etc. A pesquisa foi realizada em 20 de janeiro de 2015 e não teve pretensão maior do que ser ilustrativa.
} 
faz recordar Oliveiro Toscani, a publicidade em nossas sociedades envolve-nos cada vez mais com sua força, a força de um "cadáver perfumado" (TOSCANI, 1996, p. 40).

Quando dizemos haver tal apelo comercial, consideramos que boa parte dos livros hoje é construída tendo muito do discurso publicitário ${ }^{8}$ (ninguém publica um livro sem o desejo de ser lido; para ser lido, não basta apenas escrevê-lo, é preciso colocá-lo em circulação nos espaços adequados), do qual fazem parte a propaganda e o marketing. Assumimos, tal qual McCracken (2003), que na publicidade há uma forte relação entre um bem de consumo (um livro, por exemplo) e certa representação de mundo materializado num texto publicitário em particular. Para o autor, o sucesso de uma campanha publicitária leva em consideração a capacidade de articular certo desejo por parte do consumidor em potencial (questionando-se: qual valor simbólico esse sujeito atribui ao bem?) e demais características existentes no mundo culturalmente definido. Ou seja, a publicidade deve suprir os indivíduos com o necessário para a autorrealização destes. Dito de outro modo, se considerarmos que existe um valor atribuído a Bakhtin numa determinada cultura (acadêmica: linguistas, literatos, sociólogos, filósofos, etc.), para que um produto sobre ele seja desejável, precisa trazer elementos que mexam com a estabilidade ${ }^{9}$. Logo, o discurso publicitário é aquele que, nas sociedades modernas, não apenas vende produtos, serviços ou ideias isoladas, mas desejos, sonhos, ilusões, não raramente a partir de polêmicas.

Diferentemente, porém, de estudar o verbal e o não verbal separadamente, como é mais comum, aqui analisamos as capas na articulação entre a dimensão linguística (escrita) e não linguística (imagem, cores). Nossa sustentação baseia-se na conjectura de que, no cenário atual dos impressos (livros, revistas, jornais), as capas recebem um tratamento especial. O resultado de sua produção - com condições de trabalho diversificadas (de cores, de tipos, de diagramações, etc.) disponíveis aos profissionais envolvidos - contribuem de maneira determinante para a arquitetura de sentidos.

Neste trabalho, portanto, nos interessa a dimensão verbo-visual das capas enquanto enunciados, isto é,

[a] dimensão em que tanto a linguagem verbal como a visual desempenham papel constitutivo na produção de sentidos, de efeitos de sentido, não podendo ser separadas, sob pena de amputarmos uma parte do plano de expressão e, consequentemente, a compreensão das formas de produção de sentido desse enunciado, uma vez que ele se dá a ver/ler, simultaneamente. (BRAIT, 2013, p. 44).

\footnotetext{
8 Ocorre o mesmo fenômeno na produção/divulgação/comercialização de qualquer espetáculo: futebolístico, teatral, cinematográfico, dentre outros. Há sempre uma equipe disposta a tornar o conteúdo, digamos, mais desejável ao público.

${ }^{9}$ Está pressupondo nesta formulação que, por ser Bakhtin um teórico-crítico (e não um autor de romances do tipo best-seller, p.ex.), seus livros tenham leitores específicos, sendo predominantemente acadêmicos. Dentre estes, há os curiosos, os leitores eventuais, e os especialistas, que fazem de Bakhtin, Bakhtin; ou seja, aqueles que não só leem o autor, mas fazem com ele avançar suas teorias. Defendemos que, dentre os leitores de Bakhtin (e do chamado Círculo), os compradores de seus livros, fazem-no mais por indicação, necessidade científica, do que pela causa de uma campanha publicitária. Isso não impede, todavia, de que editoras, considerando suas políticas comerciais específicas, se dediquem mais ou menos às questões estéticas dos produtos que comercializa.
} 
$\mathrm{Na}$ perspectiva de análise dialógica aqui adotada, o verbal e o visual serão analisados como partes do mesmo conjunto produtor de sentidos. Essa perspectiva de análise é bakhtiniana, quer dizer, encontra-se fundamentada em trabalhos do pensador russo e de brasileiros. Pelas contribuições de Beth Brait, investigamos os sentidos a partir da dimensão verbo-visual de enunciados ${ }^{10}$.

Por "capa", compreendemos o que se chama tecnicamente de "primeira capa". Para Araújo (2000), a estrutura externa de um livro tem por função salvaguardar suas páginas internas ou miolo. É, consoante esse autor, uma parte extratextual, sendo composta por: primeira capa (parte externa, destinada à impressão de informações como título e subtítulo, nome do autor, editora, bem como apresentação de ilustrações); segunda capa (verso da primeira capa, geralmente não é utilizada); terceira capa (verso da quarta capa, também não utilizada para impressão); quarta capa ou contracapa (parte oposta da capa, que pode ou não ter informações impressas); primeira orelha (dobra da primeira capa); segunda orelha (dobra da quarta capa); lombada (lateral do livro); e sobrecapa (estrutura opcional ao livro, de apelo promocional e/ou estético).

Cada capa de um livro mantém, em geral, uma relação inalienável com ele, não podendo ser considerada uma entidade autônoma (SOBRAL, 2010). Dizemos "em geral" porque, ao enunciá-la, a colocamos, pelo menos para os enunciados aqui analisados, com certa autonomia em relação ao livro. Neste sentido, consideraremos as capas, neste texto, como sendo enunciados relativamente dependentes do conteúdo expresso no miolo. Em outros termos, defendemos que esses enunciados possuem características internas, de tal modo que seu autor (quase nunca o autor-pessoa do livro) "manifesta sua individualidade, sua visão do mundo, em cada um dos elementos estilísticos do desígnio que presidia à sua obra" (BAKHTIN, 2003, p. 298). As características internas contribuem, em síntese, para fazer de cada analisada, uma capa distinta das demais.

A seguir, descrevemos a capa das edições suíça, brasileira e espanhola, e apresentamos as análises.

\section{AS FACES DE BAKHTIN: DESCRIÇÃO E ANÁLISE ${ }^{11}$}

$\mathrm{Na}$ edição suíça ${ }^{12}$, de 2011, a capa possui formato retangular, sendo predominantemente branca, com os nomes dos autores no topo: na primeira linha, em caixa alta, JEAN-PAUL BRONCKART e, na segunda, CRISTIAN BOTA. Logo

\footnotetext{
${ }^{10}$ Para evitar um texto excessivamente parafraseado, indicamos, dentre outras obras referenciadas ao final deste artigo, Brait (2013), que faz uma sustentação a respeito da importância de Bakhtin e demais membros do Círculo para se pensar, teórica e metodologicamente, uma teoria da linguagem em geral, e não apenas uma teoria da linguagem verbal.

${ }^{11}$ Embora, particularmente, reconheçamos que o ideal fosse reproduzir aqui as capas, não o fizemos para não incorrer, possivelmente, em problemas de direitos autorais. Essa questão será facilmente superável por dois motivos: primeiro, porque indicamos em nota de rodapé o endereço virtual onde se podem localizar as capas analisadas; depois, as facilidades atuais permitem ao leitor encontrá-las facilmente, sem mesmo passar pelas indicações por nós fornecidas.

12 A capa pode ser visualizada no site da editora DROZ: <http://www.droz.org/france/fr/46309782600005456.html>. Acesso em: 2 fev. 2015.
} 
abaixo, também em caixa alta e fonte maior, o título centralizado BAKHTINE / DÉMASQUÉ e, nas linhas seguintes, o subtítulo: Histoire d'un menteur, d'une escroquerie et d'un délire collectif. No meio da página, há uma figura, num efeito Arcimboldo $^{13}$, e, no pé da página, a referência à editora DROZ, de Genebra, Suíça. Do lado esquerdo, escrito em branco numa tarja preta, o nome da coleção (Titre Courant) e a reprodução de uma ilustração medieval, que também aparece no frontispício da página virtual da editora ${ }^{14}$.

A ordem enunciativa dos autores é significativa. Em primeiro lugar, aparece Jean-Paul Bronckart e, na linha abaixo, Cristian Bota, forma que se manterá na edição brasileira, demonstrando certa hierarquia acadêmica. Embora na edição espanhola não haja sobreposição, por terem sido colocados os nomes em linha horizontal, o de Bronckart aparece enunciado antes. Próprios das relações de poder, esses ordenamentos se justificam por ser, o primeiro, professor honorário da Universidade de Genebra, internacionalmente conhecido na área de Linguística Aplicada e afins, de modo particular por ser um dos principais responsáveis pela corrente de estudos da linguagem chamada Interacionismo Sociodiscursivo ${ }^{15}$. Bota é, por sua vez, colaborador científico na mesma universidade, tendo sido orientado por Bronckart numa tese de doutorado defendida em 2011 (mesmo ano da publicação do livro em análise), sob o título Saberes, textos e aprendizado acadêmico: para uma análise sociodiscursiva do trabalho de validação para as aulas. ${ }^{16}$ Portanto, independente da forma de condução da pesquisa, recaem sobre Bronckart, por sua maior representatividade no cenário acadêmico e científico, as críticas mais contundentes.

No título, o termo "DÉMASQUÉ" (retirar a máscara) remete, talvez sobremaneira, ao teatro (ou à teatralização), à prática teatral de encobrir o rosto com uma máscara. É recurso cênico que, com o tempo, por esconder total ou parcialmente o rosto, passou a significar dúvida, engano, por se tentar, pelo uso de máscara, ocultar a identidade (no teatro grego, inclusive de gênero), a expressão dos sentimentos. Desmascarar teria, assim, a pretensão de revelar o ocultado. O uso da máscara é, em artes cênicas, recurso consciente e não negativo. Quem a usa, faz isso por motivos não

\footnotetext{
${ }^{13}$ Efeito Arcimboldo: O que significa ver um rosto humano onde há animal(is)? Ao olhar, se vê uma dominação do humano sobre a forma animal ou o contrário? Trata-se de uma humanização do animal ou uma animalização do humano? Há, pois, um descentramento do humano? Em relação ao assunto, pode-se consultar a obra The Arcimboldo effect: transformations of the face from the sixteenth to the twentiethcentury, organizada por Cacciari. Além de imagens produzidas por Giuseppe Arcimboldo (1527-1599), o livro apresenta, na primeira parte, artigos que procuram situar a obra do artista italiano de acordo com correntes filosóficas, científicas, políticas, artísticas do período de 1500-1650. Na segunda parte, alguns autores estudam o "efeito Arcimboldo" em obras localizadas entre os anos de 1800-1987. Cf. Cacciari et al (1987).

${ }^{14}$ Na página da editora, esta é apresentada como especializada na publicação de trabalhos acadêmicos em estudos medievais e humanísticos, além de críticas literárias. Disponível em: $<$ http://www.droz.org/eur/fr/>. Acesso em: 2 jan. 2015.

${ }^{15}$ Sobre o Interacionismo Sociodiscursivo, pode-se consultar, entre outras fontes, Bronckart (1999) e também Guimarães; Machado; Coutinho (2007).

${ }^{16}$ Em francês: Savoirs, textes et apprentissages en milieu universitaire. Pour une analyse socio-discursive de travaux de validation pour les cours. Disponível em: <http://archive-ouverte.unige.ch/unige:18458>. Acesso em: 20 nov. 2014.
} 
fortuitos. A máscara tem, logo, importância na composição da trama cênica. Ao fím do espetáculo, é retirada.

No caso do livro de Bronckart e Bota, os autores defendem que Bakhtin colocou, deliberadamente, uma máscara, e que os autores (o trabalho de Bronckart e Bota, precisamente) vieram desmascarar, contar a verdadeira história (o que eles dizem ser). Máscara assume, pois, valor negativo; desmascarar, positivo. Embora retomemos a questão da "máscara" mais adiante, há, no ato de desmascarar, certa prepotência se assumirmos que essa ação é uma violência. Enquanto prática, a máscara tem uma função particular em determinado espetáculo (e em outros rituais sociais). Tão logo essa aplicação se encerre, o indivíduo tira do próprio rosto as marcas que ajudaram o ator a construir o personagem: indivíduo-ator-personagem. Ou seja, faz parte das práticas cênicas tirar a máscara. Para Bronckart e Bota, o "ator" Bakhtin de modo intencional não tirou a máscara após suas encenações, daí considerem o indivíduo mentiroso e fraudulento; cabendo a eles a ação de desmascará-lo.

Em nossa sociedade, desmascarar alguém sempre tem um quê de superioridade pois, no ato em si, há supervalorização da ação ${ }^{17}$ do eu sobre o outro. Independente do conteúdo antecipado por textos oriundos dessa prática, em todos eles está pressuposta essa arrogância, às vezes desprezo, do eu em relação ao outro justamente por deixar transparecer que o "eu" tem o poder de trazer à luz o que estava na sombra (encoberto pela máscara).

O subtítulo da obra (Histoire d'un menteur, d'une escroquerie et d'un délire collectif), sendo elemento indissociável do título, reforça essa tese. A máscara está com o mentiroso (só permanece mascarado aquele que tenta enganar, esconder a própria identidade) e com o fraudulento (a fraude pressupõe completa deliberação, má-fé de quem frauda), sendo alimentada por um delírio coletivo.

Para campos do saber como a psicanálise, o delírio (de "delírio coletivo") é uma das manifestações dos transtornos esquizofrênicos (ou de outras doenças mentais), em que o indivíduo crê firmemente numa "falsa crença". Freud afirmava que "o delírio se apresenta como um remendo colocado no lugar onde originalmente havia surgido uma fenda no vínculo do Eu com o mundo exterior" (FREUD, 2007, p. 97). Ou seja, trata-se de uma forma de reconstrução da realidade perdida ${ }^{18}$, sendo, o delírio, um sintoma.

A respeito do "delírio coletivo", Bronckart e Bota, quando tratam no capítulo 5 das "pistas de uma provável verdade", afirmam:

[...] O ditirambo fundador de Ivanov (1973), a monstruosa "montagem” de Todorov (1981), a fabricação da obra bakhtiniana proposta por Clark e Holquist (1984b), assim como grande parte dos debates que alimentaram a Bakhtin Industry nos anos 1980/1990 estão literalmente alicerçados na mentira, no amálgama deliberado de temas e orientações de

\footnotetext{
${ }^{17} \mathrm{Na}$ Internet, é possível colher aleatoriamente alguns enunciados do tipo "Juca Kfouri desmascara Aécio Neves", "Stiglitz desmascara o falso êxito das políticas de "austeridade"“, "A justiça eleitoral já desmascarou Lúdio", "Almirante que desmascarou atentado do Rio Centro" (grifos nossos), que demonstram essa "força" da ação "desmascarar".

${ }^{18}$ Sobre o "delírio", pode-se consultar, além do próprio Freud citado, Lacan (1988), que retoma algumas teses freudianas. Sugerimos também Jorge (2010), para uma visão geral do “delírio”, e Cabas (2010), para uma visão mais centrada na questão do sujeito.
} 
desenvolvidos nos textos de Medvedev e Volóshinov e dos temas e orientações identificáveis nos pretensos escritos de Bakhtin. [...]

A mentira é um dos fermentos do delírio, e é realmente de um delírio coletivo impressionante que resultam vários comentários ocidentais da questão, de suas causas e consequências [...] que não teremos o despudor de comentar (BRONCKART; BOTA, 2012, p. 237, grifos dos autores).

Este fragmento é um exemplo de como há passagens no texto de Bronckart e Bota que foram construídas pela mobilização de elementos próprios do teatro (ou do literário): "ditirambo" (no teatro grego, canto de coral em honra a Dionísio) e "montagem" são dois exemplos. As capas (título, subtítulo, imagem, cores) do texto de Bronckart e Bota faz-nos lembrar de que todo espetáculo é uma perspectiva; talvez por isso o tom frequentemente panfletário, irônico, sarcástico assumido pelos autores. O delírio é, para os autores, fruto de uma construção, tal qual o enredo de uma peça, de uma história, de uma trama conspiratória, escrito a várias mãos, das quais eles apontam nominalmente Ivanov, Todorov, Clark e Holquist, e outros que, embora não tendo um nome, são reconhecidos como "debatedores" da/na Indústria de Bakhtin (Bakhtin Industry).

No entanto, uma questão pontual em relação ao delírio, e que está manifestada no Manual Diagnóstico e Estatístico de Transtornos Mentais (DSM-IV, 1995), elaborado pela Associação Americana de Psiquiatria, é que o fator "cultura" é importante para diagnosticar transtornos delirantes. Em suma, para se determinar o estado mental de um indivíduo (ou de indivíduos, quando do delírio coletivo), aspectos culturais (espaciais, temporais, educacionais) devem ser levados em consideração. A falta de familiaridade com determinadas informações pode, por exemplo, interferir nos conhecimentos gerais, na memória, na orientação, etc., no diagnóstico comportamental de certo(s) indivíduo(s) e/ou grupos.

No capítulo 3 ("Filosofia da linguagem e psicologia objetiva") de Marxismo $e$ Filosofia da Linguagem, há toda uma discussão apresentada por Volochinov sobre "individual" e "social", do qual reproduzimos este trecho:

\footnotetext{
'Social' está em correlação com 'natural': não se trata aí do indivíduo enquanto pessoa, mas do indivíduo biológico natural. $\mathrm{O}$ indivíduo enquanto detentor dos conteúdos de sua consciência, enquanto autor dos seus pensamentos, enquanto personalidade responsável por seus pensamentos e por seus desejos, apresenta-se como um fenômeno puramente sócioideológico. Esta é a razão porque o conteúdo do psiquismo 'individual' é, por natureza, tão social quanto a ideologia e, por sua vez, a própria etapa em que o indivíduo se conscientiza de sua individualidade e dos direitos que lhe pertencem é ideológica, histórica, e internamente condicionada por fatores sociológicos. Todo signo é social por natureza, tanto o exterior quanto o interior. (BAKHTIN/VOLOCHINOV, 2002, p. 58).
}

O subtítulo da obra permite-nos afirmar que seus enunciadores sejam encarados como locutores-historiadores. Trata-se de uma obra de história, devendo ser lida como história, tendo como objeto um mentiroso mascarado (no caso, Bakhtin) que frauda e é partícipe de conspiração? Na expressão "História de x", "x" pode ser agente e/ou paciente? Isto é, a locução reforça a tese de história contada por um mentiroso e/ou sobre ele? "Fraude" e "delírio coletivo" teriam ou não o mesmo estatuto semântico de 
"mentiroso"? O livro em questão contém - ao dizer/mostrar outra história ("história de") - a verdade? Conquanto sejam questões em aberto, estamos esboçando, neste texto, algumas possíveis respostas.

A imagem centralizada, por sua vez, nos faz lembrar de certo tipo de composição artística ligada ao italiano Giuseppe Arcimboldo. (Cf. Nota de rodapé 13). De autoria da artista chinesa Fay $\mathrm{Yu}$, conforme informações na folha de rosto da edição suíça, a ilustração parece ser a caricatura de um homem, com expressões senis, cujos cabelos têm a forma de escorpião (ou os cabelos do ilustrado fazem lembrar escorpião, ou escorpião faz lembrar os cabelos do ilustrado...). Podem ser identificados a representação de óculos e pequenos balões, como nas Histórias em Quadrinhos, em que aparecem letras aparentemente desconexas (índices de diálogos?), num dos quais (o da direita) há o reflexo de um (terceiro) olho; lábios pintados (ao que parece, pelo reforço do traço); gravata (ou colarinho) de bolinhas. Trata-se de uma fantasia?

A caricatura mantém sempre relação com o retratado, ou seja, nas imagens que se formam pela prática de caricaturar, muito embora os acentos hiperbólicos que recebe, há índices que fazem lembrar o indivíduo. O dicionário Houaiss on-line ${ }^{19}$, por exemplo, define caricatura como "desenho de pessoa ou de fato que, pelas deformações obtidas por um traço cheio de exageros, se apresenta como forma de expressão grotesca ou jocosa". No caso, o que haveria de Bakhtin na caricatura? Por que desmascarar, se não há máscara? (Bakhtin descaricaturado?). A ilustração parece não apresentar traços que façam lembrar Bakhtin (Figura 2), diferente da edição espanhola, a não ser como uma visão distorcida do modelo.

No caso da edição brasileira ${ }^{20}$, há informações sobre a ilustração de capa e da quarta capa; no primeiro caso, em informações disponíveis na folha de rosto desse livro, apenas se diz que o projeto gráfico e a capa são construções de Andreia Custódio ${ }^{21}$; no segundo, cita-se o trabalho de Fay Yu presente, primeiramente, na edição suíça. Essa capa também tem formato retangular, sendo o verde predominante. No alto, do lado esquerdo, vê-se a metade de uma máscara que, projetando um efeito de luz da direita para a esquerda, cria um efeito de sombra e, também, de completude. Abaixo, na mesma linha e igualmente de modo sobreposto, grafa-se Jean-Paul Bronckart e Cristian Bota. Na sequência, aparece o nome BAKHTIN, em caixa alta, e na linha a palavra ODARACSAMSED (de trás para frente e de cabeça para baixo), sendo seguida, em fonte menor, do subtítulo história de um mentiroso, de uma fraude, de um delírio coletivo.

\footnotetext{
${ }^{19}$ Disponível em: <http://houaiss.uol.com.br/busca?palavra=caricatura >. Acesso em: 20 jan. 2015.

20 A capa pode ser visualizada no site da editora Parábola: < http://www.parabolaeditorial.com.br/>. [último] Acesso em: 02 fev. 2015.

${ }^{21}$ No perfil do Facebook da empresa, Andreia Custódio é descrita como sócia-diretora, sócia-executiva, sócia-designer da Parábola Editorial, às vezes como co-fundadora (junto com Marcos Marcionilo), designer, executiva de marketing. Disponível em: <https://www.facebook.com/parabolaeditorial $\geq$. Acesso em: 20 jan. 2014.
} 
A edição espanhola ${ }^{22}$ foi traduzida por Cristina Ridruejo Ramos e Eric Jalain Fernández, publicada pela Antonio Machado Libros, de Madri, em 2013. Também em formato retangular $(24 \times 17 \mathrm{~cm})$, foi construída num fundo de cor laranja, numa encadernação rústica, com dois destaques: no primeiro, num quadrado de fundo azul, os nomes, no alto, de Jean-Paul Bronckart escrito em cor laranja escuro e, na mesma linha, tipo de letra e cor, Cristian Bota. Logo abaixo, o título (Bajtín desenmascarado) em fonte maior do que a usada no nome dos autores, e nas duas linhas seguintes o subtítulo (historia de un mentiroso, una estafa [e na linha de baixo] y um delirio colectivo), ambos escritos na cor branca. $\mathrm{O}$ segundo destaque fica a cargo da reprodução de uma fotografia de Bakhtin, em que este é clicado vestido de preto, sobre o fundo escuro. Na estampa da edição madrilena (Figura 1), uma tira, onde se encontrariam os olhos do escritor, é destacada (rasgada) da esquerda para a direita, deixando à mostra o fundo laranja. A referência à editora aparece em forma de logotipo, alinhado à direita, entre o quadro azul e a fotografia, sendo: ANT (+ imagem da cabeça de um homem com chapéu, ocultando o restante ONIO, pelo qual deduzimos: ANTONIO) MACHADO e, na linha de baixo, o segundo nome, "Libros", escrito em verde. Do lado esquerdo, há uma seta, em azul, que se projeta de baixo ao topo da página.

Figura 1 - Recorte: capa da edição espanhola (2013)

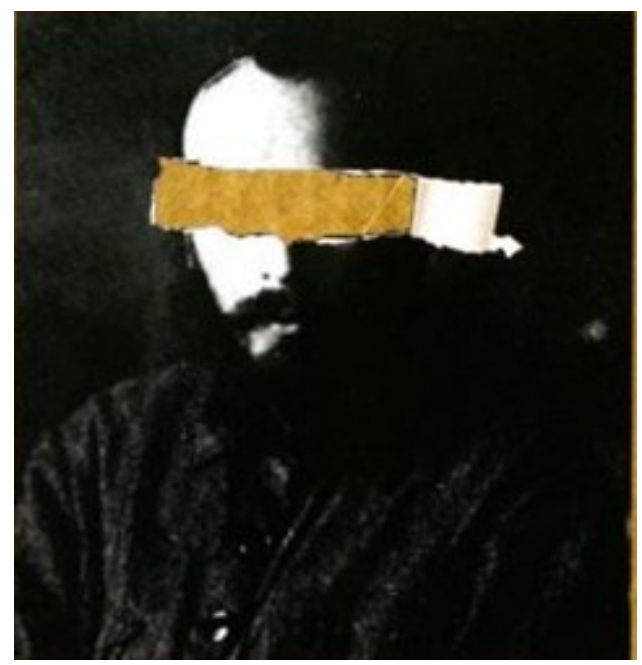

Fonte: Edição espanhola (2013).

O destaque da edição espanhola fica para a reprodução de uma (suposta) fotografia de Bakhtin, que encontramos em vários lugares, como na Wikipédia (Figura 2): 22 A capa pode ser visualizada no site da editora Antonio Machado Libros:
$<$ http://image.casadellibro.com/a/l/t0/62/9788477741862.jpg $>$. [último] Acesso em: 02 fev. 2015 . 


\section{Figura 2 - Mikhail Bakhtin}

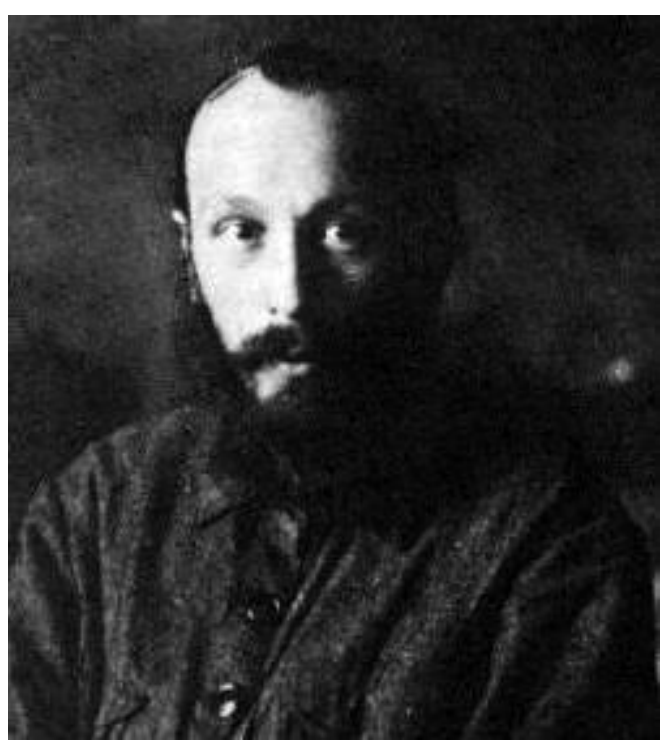

Fonte: $<$ http://pt.wikipedia.org/wiki/Mikhail_Bakhtin>

Se na edição suíça há uma espécie de caricatura; na brasileira, reproduz-se uma máscara. Na espanhola, optou-se por trazer algo mais próximo da realidade: trabalhando-se sobre uma fotografia, desejou-se produzir um efeito de veracidade contundente. O modo como fizeram a figura de "Bajtín" dialogar com o termo "desenmascarado" foi-lhe aplicando um "destaque" (retirada de uma tira) nos olhos, que dialoga com certa prática jornalística de encobri-los com uma tarja ${ }^{23}$ ou usar outro recurso técnico que os desconfigura. Identificamos o rosto a partir uma memória (Figura 2), que circula em outros meios; mas não vemos seus olhos. Para Chevalier e Gheerbrant (2009), os olhos são o órgão da "percepção sensível", e quase universalmente o "símbolo da percepção intelectual". Nas três capas, os olhos recebem algum tipo de destaque: na edição suíça, óculos; na brasileira, a máscara; na espanhola, a retirada. O que esconderiam?

$\mathrm{Na}$ edição espanhola, é o Bakhtin Spectrum (BARTHES, 1984), ou seja, “o retorno do morto" (p. 20). Neste sentido, é Bakhtin (indivíduo) tornando-se objeto. Enquanto contingência soberana - "uma dissociação astuciosa da consciência de identidade" (p. 25) -, a objetiva da câmera captura não o próprio Bakhtin, mas o resultado transforma-o num personagem, que, na capa espanhola, é ressignificado negativamente.

Se na edição suíça há uma caricatura, na brasileira se vê (a metade de) uma máscara. A meia-máscara se completa com sua sombra. Outra diferença visível é o termo "desmascarado". Na edição brasileira é inteligível apenas se lido de trás para

\footnotetext{
${ }^{23} \mathrm{O}$ uso do recurso de esconder os olhos com uma tarja preta (raramente branca ou de outra cor) não é mais recomendado no meio jornalístico, como vemos no Guia prático para jornalistas, da UNICEF (2007): "A barra negra cobrindo os olhos é frequentemente usada, mas não é o mais efectivo" (p. 4) ou neste Guia de referências para coberturas jornalísticas (ANDI, 2009), que, ao justificar o não uso da "tarja preta" para encobrir os olhos de crianças e adolescentes, diz: "Ela pode remeter a um tratamento pejorativo, dando à imagem sentido negativo" (p. 88).
} 
frente. E ao virar o livro de cabeça para baixo, o faz dialogar com a máscara apresentada. Esse conjunto de significantes nos remete a O fantasma da ópera, de Gaston Leroux, precisamente por conta da questão do espelho, do duplo: “[...] avaliamos a nós mesmos do ponto de vista dos outros, através do outro procuramos compreender e levar em conta os momentos transgredientes à nossa própria consciência [...]". (BAKHTIN, 2003, p. 13). É o espelho o condutor da dupla face. Da identidade. Da dissimulação. Nesse sentido, é o espelho que permite à máscara seu papel em evidência (LOPONDO; ALVAREZ, 2013).

A máscara nas sociedades em geral está presente, dentre outros, em rituais religiosos, como estuda Lévi-Strauss (1981); fúnebres, como se pode ler no texto de José Mattoso ${ }^{24}$; festivos e teatrais, tal qual encontramos em Bakhtin (1981; 2010), quando estuda a questão do carnaval/carnavalização. Além disso, como se sabe, há tempos a relação entre persona e máscara é conhecida no meio acadêmico e literário. Persona, personagem, pessoa. No teatro, a máscara é capital, em vários espetáculos, na composição de personagens. No carnaval, "a máscara traduz a alegria das alternâncias e das reencarnações, a alegre relatividade, a alegre negação da identidade e do sentido único, a negação da coincidência estúpida consigo mesmo" (BAKHTIN, 2010, p. 35). Para a psicanálise junguiana, todos nós utilizamos máscaras. Ao longo da existência individual, utilizaremos tantas quantas forem as máscaras (personas) necessárias para lidarmos com a realidade que nos cerca.

Ao partir do princípio de que todos somos personagens no/do mundo, então, sempre atuamos representando papéis sociais: professores, pais, mães, escritores, leitores, etc. A máscara é considerada, na psicanálise junguiana, um arquétipo: aquilo que pertence a todos e a ninguém; " consiste de formas preexistentes, arquétipos, que só secundariamente podem tomar-se conscientes, conferindo uma forma definida aos conteúdos da consciência" (JUNG, 2000, p. 53). Ou seja, embora cada indivíduo o vivencie (no inconsciente individual), não pode dele se apropriar plenamente, por pertencer ao inconsciente coletivo ${ }^{25}$. Os arquétipos, no inconsciente coletivo, são seu conteúdo psíquico.

A máscara, como todo arquétipo, tem seu lado positivo e negativo, e a capa brasileira do livro de Bronckart e Bota ilustra bem isso ao trabalhar luzes e sombras: do lado da máscara, a luz (inclusive a imagem recebe um tratamento plastificado para que brilhe do lado direito); do lado da sombra, a escuridão.

Do ponto de vista especular, o que esconde(ria) a máscara? Algo de monstruoso? Feio? Abominável? Tal qual a discussão bakhtiniana em torno do sujeito, visto que este se constitui dialogicamente, quem é o outro no espelho? Ou o parcialmente escondido

\footnotetext{
${ }^{24}$ Disponível em: <http://ler.letras.up.pt/uploads/ficheiros/3199.pdf $>$. Acesso em: 20 nov. 2014.

${ }^{25}$ Segundo Jung: "O inconsciente coletivo é uma parte da psique que pode distinguir-se de um inconsciente pessoal pelo fato de que não deve sua existência à experiência pessoal, não sendo portanto uma aquisição pessoal. Enquanto o inconsciente pessoal é constituído essencialmente de conteúdos que já foram conscientes e no entanto desapareceram da consciência por terem sido esquecidos ou reprimidos, os conteúdos do inconsciente coletivo nunca estiveram na consciência e portanto não foram adquiridos individualmente, mas devem sua existência apenas à hereditariedade. Enquanto o inconsciente pessoal consiste em sua maior parte de complexos, o conteúdo do inconsciente coletivo é constituído essencialmente de arquétipos" (2000, p. 53).
} 
pela máscara? Diferentemente da caricatura, que é o olhar do eu sobre o outro, ou da fotografia, que é a pessoa captura enquanto personagem (BARTHES, 1984), a máscara é uma forma de projeção do que o eu deseja. A máscara é, pois, a evidência do outro; sabe-se que por trás da máscara há algo, alguém, mas também existe o hiato. Como mencionam Lopondo e Alvarez (2013, p. 212), traduzindo Buchbinder: "a máscara é o outro de um, daquele que a porta, como daquele que a observa. É a figuração antropomórfica do fantasma, do Outro, das forças que estão além daqueles que o sujeito pode dominar". No caso da edição brasileira, há apenas máscara sem rosto, sem olhos. No entanto, não está vazia.

Outra diferença marcante é o modo como se utilizam as cores. Se na edição suíça predomina o branco, com palavras em preto; na espanhola, destaca-se o tom laranja/amarelado; na brasileira, usa-se o recurso das tonalidades de maneira mais intensa. Não é novidade que, em nossa cultura, a simbologia das cores ajuda a construir sentidos. No Ocidente, por exemplo: branco, para paz; amarelo, para energia/vitalidade; verde, para esperança.

Como observa Guimarães (2000), mobilizando a Semiótica da Cultura, a cor pode funcionar como uma informação atualizada do signo. Conforme exemplifica o autor, o cravo vermelho num jardim é apenas "cravo" de cor "vermelha", não sendo, portanto, signos, mesmo que do ponto biofísico haja a transmissão de informações: o cravo vermelho (a cor funciona biofisicamente) transmite informações necessárias à abelha, que, por sua vez, as transmite a outras abelhas. Se esse mesmo cravo for usado por um homem na lapela, então, "passa a ser um texto e o vermelho o signo deste texto e até mesmo um texto cultural" (p. 17).

$\mathrm{Na}$ edição suíça, o branco ${ }^{26}$ predominante parece funcionar como um purificador, um amenizador do possível impacto dos signos linguísticos e da caricatura. Além disso, há certa negatividade na sequência "desmascarado, mentiroso, fraude, delírio" relacionada a Bakhtin. O branco, ao qual Baudrillard (1993) chama de "cor cirúrgica virginal" (p. 40), encobre os impulsos. O verde, por sua vez, predominante na edição brasileira, é uma das cores primárias (ao lado do azul e do vermelho). O verde remete materialmente às matas, às folhagens, às águas do mar, numa associação afetiva que provoca bem-estar, serenidade, afetividade. A cor laranja, remetem-na ao Sol, significando vitalidade, energia, alegria. Por outro lado, como ainda demonstra Guimarães (2000), a alteração numa cor, mesmo que leve, aumentado ou diminuindo sua luminosidade, pode provocar uma alteração nos sentidos. Conjunto máscara, sombra, luz, cor contribuem para as impressões de sentidos.

$\mathrm{Na}$ edição brasileira, constrói-se um efeito de diminuição da luminosidade da direita para a esquerda, ao mesmo tempo em que a metade da máscara produz efeito de completude. No entanto, por causa do "efeito Gestalt", ou seja, de nossa capacidade de ver primeiro o todo, e não as partes isoladas, existe inicialmente a sensação de que não se trata de uma máscara de face única completada por sua sombra, e sim de uma máscara completa. Em outros termos, vemos antes o todo (a máscara), depois

\footnotetext{
${ }^{26}$ O branco é uma "combinação de todos os comprimentos de onda do espectro, mas, como cor, na realidade, não existe” (FARINA; PEREZ; BASTOS, 2006, p. 53).
} 
racionalizamos as partes (metade de máscara, sombra, etc.). Em lugar, pois, de partes isoladas, vemos relações (GOMES FILHO, 2004). Dito de outro modo, conforme esse autor, nosso cérebro tende "a organizar as formas em todos coerentes e unificados" ( $p$. 17).

$\mathrm{Na}$ figura da capa, visualizamos uma representação do yin-yang, que significa, na cultura oriental, a dualidade. Como aponta Gomes Filho (2004), o símbolo yin-yang marca um equilíbrio simétrico oposto, "com os pesos visuais apostos contrabalançados e distribuídos igualmente” (p. 31). Para perceber melhor essa relação, reproduzimos esta Figura 3:

Figura 3 - Manipulação da imagem da capa da edição brasileira, em branco e preto

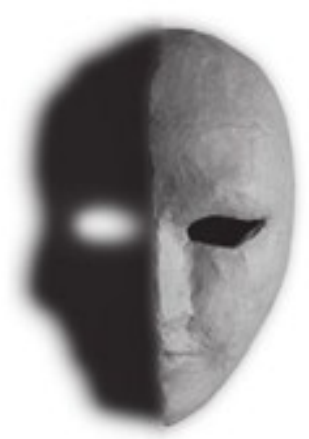

Fonte: edição brasileira.

Ao remover o colorido da máscara presente na capa, parece-nos que se destaca um ponto preto na região mais clara, e um ponto branco na mais escura, próprio do simbolismo yin-yang. Conforme Biedermann (1993), “o "yin" [esquerda] simboliza o feminino, o Norte, o frio, a sombra, a terra, a passividade, a umidade, enquanto o "yang" [direita] representa a masculinidade, o céu, o Sul, a luz, a atividade, a secura" (p. 397, grifos do autor). E acrescenta: "como expressão de dependência recíproca, é importante que haja um centro escuro (representando de novo circularmente) a parte "yang" do círculo bipartido, e um centro no claro na parte "yin"“" (p. 397).

A imagem da Figura 3 representaria essa dualidade, que encontramos na obra de Bakhtin, na qual as forças dos processos de enunciação são definidoras dos enunciados ditos. Em outros termos, a imagem da capa da edição brasileira vem reforçar a ideia de um Bakhtin múltiplo, misterioso, mas não mentiroso e fraudulento, como podemos complementar com esta afirmação:

A máscara traduz a alegria das alternâncias e das reencarnações, a alegre relatividade, a alegre negação da identidade e do sentido único, a negação da coincidência estúpida consigo mesmo; a máscara é expressão das transferências, das metamorfoses, das violações das fronteiras naturais, da ridicularização, dos apelidos; a máscara encarna o princípio do jogo da vida, está baseada numa peculiar inter-relação da realidade e da imagem, característica das formas mais antigas dos ritos e dos espetáculos (BAKHTIN, 2010, p. 35).

Em conclusão, o processo de construção da obra bakhtiniana se assenta num determinado modo de compreender a função social da máscara, como sintetizado nessa citação. 
No exercício de análise que fizemos aqui, tomando como objeto de leitura as capas das edições suíça, brasileira e espanhola do livro Bakhtin desmascarado: história de um mentiroso, de uma fraude, de um delírio coletivo (Bakhtine démasqué: Histoire d'un menteur, d'une escroquerie et d'un délire collectif; Bajtín desenmascarado: historia de un mentiroso, una estafa y un deiirio colectivo), de autoria de Jean-Paul Bronckart e Cristian Bota, chegamos a algumas considerações, assim destacadas:

a) Embora as capas falem do mesmo objeto (a história de/sobre Bakhtin), ambas oferecem ao leitor elementos diferentes para travarem um primeiro contato com essa história. Neste sentido, capas possuem um lugar autorizado e legitimado de dizer " $x$ " ou " $y$ " em nome de grupos institucionais. Por isso, as consideramos enunciados relativamente dependentes do miolo envolvido por elas;

b) As capas do livro de Bronckart e Bota parecem significar diferentemente: 1) na edição suíça, há um "suavizamento" do peso semântico das palavras "Bakhtin" e "desmacarado", graças ao uso predominante do branco e da suposta caricatura de Bakhtin; 2) na brasileira, o recurso das cores, o efeito de luz, a inversão da palavra "desmascarado" parecem conferir-lhe um impacto na relação Bakhtin e desmascarado, se comparada à suíça; 3) na espanhola, ao trazer a fotografia, busca-se criar um efeito de verdade mais efetivo se comparada às duas outras. Em ambas, porém, há esse foco nos olhos, "símbolo da percepção intelectual".

c) As capas brasileira e suíça traduzem do universo bakhtiniano a força do espetáculo: teatral, no caso da edição brasileira; e carnavalesco, no da suíça, muito embora talvez falte a esta o multicolorido, próprio do Carnaval. Estes aspectos (carnavalesco e teatral) parecem ausentes na edição espanhola; aqui, o tratamento dado à fotografia, em preto e branco, "ocultando" os olhos parece produzir um jornalístico-policialesco.

d) A capa de um livro mantém com seu conteúdo uma relação semântica, permitindo-nos afirmar que a caricatura produzida por Fay Yu parece dialogar com o termo "Bakhtin", do título "Bakhtin Desmascarado", enquanto a criação de Andreia Custódio foca o "(des)mascarado". Na espanhola, a (desfiguração de uma) fotografia de Bakhtin parece reforçar a questão do suposto crime de Bakhtin.

e) O título e subtítulo da obra obrigaram os autores das capas a um exercício de leitura significativo, materializado, como esperamos ter demonstrado, nos enunciados verbo-visuais produzidos. $\mathrm{E}$ isso nos permite afirmar que significam diferentemente por trazerem elementos culturais distintos.

Para se compreender a importância da capa na compreensão de livro, precisamos lê-la não apenas como algo funcional (proteger o interior do livro), tampouco comercial (vender a obra). É fundamental considerá-la algo estético-discursivo, ou seja, como uma 
maneira de o ser humano dar "forma à sua experiência" (BRAIT, 2013, p. 48). Daí a importância de teorias que deem conta do verbal e do visual como partes do mesmo processo de significação verbo-visual.

Muitos trabalhos humanos dependem ao mesmo tempo da força construtora de seus autores, mas também da determinação de seus críticos, dos embates ideológicos que travam e que permitem travar. Há, para encerrar, em todo sucesso literário (em sentido mais amplo) certamente competências, que lhe conferem uma visibilidade temporária ou, a depender da capacidade de fazer história de seu(s) protagonista(s), duradoura. Este último é o caso de Bakhtin.

\section{AGRADECIMENTOS}

Compartilho, posto que todo trabalho é coletivo, as qualidades deste texto com Adair V. Gonçalves (UFGD), Beth Brait (PUC-SP) e Grenissa B. Stafuzza (UFG), pelos diálogos pertinentes, e com os pareceristas da LEMD que, pelo trabalho voluntário, ajudam no aperfeiçoamento textual. Os defeitos que persistirem são meus.

\section{REFERÊNCIAS}

ANDI. Guia de referências para coberturas jornalísticas. 2009. Disponível em: $<$ http://www.andi.org.br/file/50179/download?token=N_Q0_4YL>. Acesso em: 15 nov. 2014.

ARAÚJO, E. A construção do livro. Rio de Janeiro: Nova Fronteira, 2000.

ARÁN, P. O. A questão do autor em Bakhtin. Bakhtiniana, São Paulo, Número Especial, p. 4-25, jan./jul. 2014. Disponível em: <http://revistas.pucsp.br/index.php/bakhtiniana/issue/view/1255/showToc >. Acesso em: 20 nov. 2014.

BAKHTIN, M. M. Problemas da Poética de Dostoievski. Trad. de Paulo Bezerra. Rio de Janeiro: Forense Universitária, 1981.

Estética da criação verbal. 4. ed. Trad. de Paulo Bezerra. São Paulo: Martins Fontes, 2003. A cultura popular na Idade Média e no Renascimento: o contexto de François Rabelais. 7. ed.

Trad. de Yara Frateschi Vieira. São Paulo: Hucitec, 2010.

; VOLOCHINOV, V. N. Marxismo e filosofia da linguagem: problemas fundamentais do método sociológico na ciência da linguagem. Trad. de Michel Laud e Yara F. Vieira. 9. ed. São Paulo: HUCITEC, 2002.

BARTHES, R. A câmara clara. Trad. de Júlio Castañon Guimarães. Rio de Janeiro: Nova Fronteira, 1984.

BIEDERMANN, H. Dicionário ilustrado de símbolos. Trad. de Glória Paschoal de Camargo. São Paulo: Melhoramentos, 1993.

BAUDRILlARD, J. O sistema dos objetos. Trad. de Zulmira Ribeiro Tavares. São Paulo: Perspectiva, 1993.

BRAIT, B. Análise e teoria do discurso. In: (Org.). Bakhtin - outros conceitos-chave. São Paulo: Contexto, 2006a. Introdução. Alguns pilares da arquitetura bakhtiniana. In: (Org.). Bakhtin: ConceitosChave. São Paulo: Contexto, 2006b. Olhar e ler: verbo-visualidade em perspectiva dialógica. Bakhtiniana, São Paulo, v. 8, n. 2, p. $43-$ 66, jul./dez. 2013. Disponível em: <http://www.scielo.br/pdf/bak/v8n2/04.pdf>. Acesso em: 26 out. 2014. (Org.). Bakhtin e o Círculo. São Paulo: Editora Contexto, 2009a. (Org.). Bakhtin: Dialogismo e Polifonia. São Paulo: Contexto, 2009 b. 
BRONCKART, J.-P. Atividade de linguagem, texto e discursos: por um interacionismo sócio-discursivo. Tradução de Anna Raquel Machado e Péricles Cunha. São Paulo: EDUC, 1999.

Les différentes facettes de l'interactionnisme socio-discursif. Calidoscópio - Revista de Linguística Aplicada, n. esp.: International Congress on Language and Interaction, p. 22-25, 2006.

; BOTA, C. Bakhtine démasqué. Histoire d'un menteur, d'une escroquerie et d'un délire collectif. Genebra: Droz, 2011.

Bakhtin desmascarado: história de um mentiroso, de uma fraude, de um delírio coletivo. Tradução Marcos Marcionilo. São Paulo: Parábola, 2012. Bajtín desenmascarado: historia de un mentiroso, una estafa y un delirio colectivo.

Madrid: Antonio Machado Libros, 2013.

Disponível em: Bakhtin desmascarado: Reação às críticas à obra. Tradução de Marcos Bagno

$<$ http://www.parabolaeditorial.com.br/website/index.php?option=com_content\&view=article\&id $=444 \% 3$ Abakhtin-desmascarado-reacao-as-criticas-a-obra\&catid=65\%3Ablog-2\&Itemid=131>. Acesso em: 18 dez. 2014.

BRUCHARD, D. A encadernação. Disponível em:

<www.escritoriodolivro.org.br/historias/encadernacao.html>. Acesso em: 15 jun. 2014.

CABAS, A. G. O sujeito na psicanálise de Freud a Lacan: da questão do sujeito ao sujeito em questão.

32. ed. Rio de Janeiro: Jorge Zahar Ed., 2010.

CACCIARI, M. et al. The Arcimboldo effect: transformations of the face from the sixteenth to the twentieth-century. Milão: Bompiani, 1987.

CHEVALIER, J.; GHEERBRANT, A. Dicionário de Símbolos. 23. ed. Rio de Janeiro: J. Olympio, 2009.

DSM-IV. Manual diagnóstico e estatístico de transtornos mentais. Porto Alegre: Artes Médicas, 1995.

JORGE, M. A. C. Fundamentos da psicanálise de Freud a Lacan. V. 2: a clínica da fantasia. Rio de Janeiro: Zahar, 2010.

FARINA, M.; PEREZ, C.; BASTOS, D. Psicodinâmica das cores em comunicação. 5. ed. rev. e ampl. São Paulo: Edgard Blücher, 2006.

FOUCAULT, M. O que é um autor? In: . Ditos \& Escritos III - estética: literatura e pintura, música e cinema. Rio de Janeiro: Forense Universitária, 2001. p. 264-298.

FRANÇOIS, F. Bakhtin completamente nu. Bakhtiniana, São Paulo, Número Especial: p. 173-183, jan./jul. 2014. Disponível em: <http://revistas.pucsp.br/index.php/bakhtiniana/article/view/19739>. Acesso em: 20 dez. 2014.

FREUD, S. Escritos sobre a psicologia do inconsciente. V. 3. Rio de Janeiro: Imago, 2007.

GOMES FILHO, J. Gestalt do objeto: sistema de leitura visual da forma. 6. ed. São Paulo: Escrituras Editora, 2004.

GUIMARÃES, L. A cor como informação: a construção biofísica, linguística e cultura da simbologia das coeres. São Paulo: Annablume, 2000.

GUIMARÃES, A. M. M.; MACHADO, A. R.; COUTINHO, A. (Org.). O interacionismo sociodiscursivo: questões epistemológicas e metodológicas. Campinas, SP: Mercado de Letras, 2007.

JUNG, Carl G. Os arquétipos e o inconsciente coletivo. 2. ed. Trad. de Maria Luíza Appy e Dora Mariana R. F. da Silva. Petrópolis, RJ: Vozes, 2000.

(Org.). O homem e seus símbolos. 6. ed. Trad. de Maria Lúcia Pinho. Rio de Janeiro: Nova Fronteira, 2008.

LACAN, J. O Seminário, Livro III: As Psicoses [1955-56]. Rio de Janeiro: Jorge Zahar, 1988.

LÉVI-STRAUSS, C. A Via das Máscaras. Lisboa: Editorial Presença, 1981.

LEROUX, G. O Fantasma da ópera. Rio de Janeiro: Ediouro, 2005.

LOPONDO, L.; ALVAREZ, A. G. R. Entre o rosto e a máscara: identidades e verdades em tensão. Acta Scientiarum. Language and Culture. v. 35, n. 3, 2013. Disponível em:

$<\mathrm{http}$ //periodicos.uem.br/ojs/index.php/ActaSciLangCult/article/view/16212>. Acesso em: 5 nov. 2014.

MEDVIÉDEV, I. P.; MEDVIÉDEVA, D. A. O Círculo de M. M. Bakhtin: sobre a fundamentação de um fenômeno. Bakhtiniana, São Paulo, núm. Espe., p. 173-183, jan./jul. 2014. Disponível em:

$<$ http://revistas.pucsp.br/index.php/bakhtiniana/article/view/11535>. Acesso em: 20 dez. 2014. 
MCCRACKEN, G. Cultura e Consumo: novas abordagens ao caráter simbólico dos bens e das atividades de consumo. Rio de Janeiro: Mauad, 2003.

NOSSIK, S. Resenha. Bakhtiniana, São Paulo, núm. esp., p. 173-183, jan./jul. 2014. Disponível em: $<$ http://revistas.pucsp.br/index.php/bakhtiniana/issue/view/1255/showToc>. Acesso em: 20 nov. 2014.

SOBRAL, A. Texto, discurso, gênero: alguns elementos teóricos e práticos. 2010. Disponível em: $<$ http://seer.uniritter.edu.br/index.php/nonada/article/viewFile/264/177>. Acesso em: 15 nov. 2014.

SOMOZA, J. C. Dafne Desvanecida. Barcelona: Destino, 2000.

TOSCANI, O. A publicidade é um cadáver que nos sorri. Rio de Janeiro: Ediouro, 2003.

UNICEF. Guia prático para jornalistas: cobertura jornalística sobre a violência, abuso sexual e exploração da criança. Disponível em:

$<$ http://www.unicef.org/mozambique/Guia_para_jornalistas_violencia_contra_criancas_190607.pdf $>$. Acesso em: 20 dez. 2014.

ZENKINE, S. Os desmascaradores incompetentes. Bakhtiniana, São Paulo, núm. esp., p. 173-183, jan./jul. 2014. Disponível em:

<http://revistas.pucsp.br/index.php/bakhtiniana/issue/view/1255/showToc>. Acesso em: 20 nov. 2014

Recebido em: 04/08/15. Aprovado em: 28/10/15

Title: Bakhtin's faces: a discourse analysis of book covers

Author: Marcos Lúcio de Sousa Góis

Abastract: This essay presents a discursive analysis of the Swiss, Brazilian and Spanish covers of the book by Jean-Paul Bronckart and Cristian Bota, titled Bakhtin unmasked: story of a liar, a fraud, a collective delirium. Founded on the dialogical perspective of discourse and dialoguing with psychoanalysis and semiotics, this article aims to understand the effects of meanings produced by these statements. There are two reasons for this proposal: first, Bronckart and Boot's book caused some academic inconvenience; second, this inconvenience generated numerous debates about the nature of the work in focus. Although the covers apparently treat about the same object, both offer the reader different elements to wage a first contact with this story. It is hoped that the analysis, more than increasing the controversy concerning the dispute in which Bronckart and Bota and their critics were involved, also reinforces the thesis that the author-creator Bakhtin transcends the individual Bakhtin.

Keywords: Dialogical Discourse Analysis. Meanings. Statements. Covers.

Título: Las faces de Bajtín: un análisis discursivo de cubiertas de libros

Autor: Marcos Lúcio de Sousa Góis

Resumen: Este artículo presenta un análisis discursivo de las cubiertas suiza, brasileña y española del libro de Jean-Paul Bronckart y Cristian Bota, titulado Bajtín desenmascarado: historia de un mentiroso, de un fraude, de un delirio colectivo. Basado en la perspectiva dialógica del discurso y dialogando con la psicoanálisis y la semiótica, tiene por objetivo comprender los efectos de sentidos producidos por eses enunciados. Son dos razones para propuesta: primero, el libro de Bronckart y Bota he causado cierto malestar académico; segundo, este malestar generó innúmeros debates a respeto de la naturaleza de la obra en foco. Aunque las cubiertas aparentemente tratar con el mismo objeto, ambas ofrecen al lector elementos diferentes para hacer un primer contacto con esa historia. Se espera, con este análisis, alá más de alimentar el diálogo a respeto de la controversia en la cual se viran involucrados Bronckart y Boot y sus críticos, reforçar la tesis de que el autorcreador Bajtín trasciende el individuo Bajtín.

Palabras-clave: Análisis Dialógico del Discurso. Enunciados. Sentidos. Cubiertas de libros. 